\title{
Technical Proposal for Revitalizing the Eastern Buddha Statue in Bamiyan
}

\author{
Kosaku Maeda, Shigeyuki Okazaki, Noritoshi Sugiura, Aya Yamaguchi, \\ Masaaki Miyasako, Kazuya Yamauchi, Kenji Tamai, Shigeo Aoki, \\ and Takashi Inoue
}

\begin{abstract}
Buddhist site of Bamiyan is one of the most important historical and ethnical heritage in Afghanistan. Two colossal Buddhas arranged in the east and the west of the cliff were the brilliant symbol of the Bamiyan valley and emitted the monumental meaning of the westward spread of Buddhism. They were exactly the human heritage with history and memory. Unfortunately they were destroyed in 2001 during the inner war. All the mural paintings of the niches of the colossal Buddhas were completely destroyed and disappeared, but fortunately the back walls of the statues of Buddhas were narrowly left. Since 2002, the collaborative and cooperative efforts to protect and restore the world cultural heritage of Bamiyan have been promoted by UNESCO, International Experts, the Government of Afghanistan and Bamiyan Province. And now, we confront the difficult problem of the reconstruction or revitalization of the Buddha statues. It goes without saying that the reconstruction/revitalization of the colossal Buddha would be an effective tourism resource for Bamiyan Province. The reconstruction of Buddha should be carried out only upon all national agreements of Afghanistan and would be based on bold ideas, implementing the innovative technologies to inspire.
\end{abstract}

Published jointly by the United Nations Educational, Scientific and Cultural Organization (UNESCO), 7, place de Fontenoy, 75007 Paris, France, the UNESCO Office in Kabul, ICON Compound, Supreme Road, Off Jalalabad Road, PD 9, Kabul, Afghanistan, and Springer Nature Switzerland AG, Gewerbestrasse 1, 6330 Cham, Switzerland.

K. Maeda $\cdot$ M. Miyasako $\cdot$ K. Tamai $\cdot$ S. Aoki $\cdot$ T. Inoue Public Collaboration Center, Tokyo University of the Arts, Tokyo, Japan e-mail: isca-maeda@m2.dion.ne.jp; miyasako@fa.geidai.ac.jp; kenji-tamai@jcom.home.ne.jp; aokisigeo@nifty.com

S. Okazaki $\cdot$ N. Sugiura $\cdot$ A. Yamaguchi $(\bowtie)$

Department of Architecture, School of Architecture, Mukogawa Women's University, Nishinomiya, Japan

e-mail: kzk6f7@mukogawa-u.ac.jp; sugiura@mukogawa-u.ac.jp;

a_ymgc@mukogawa-u.ac.jp

K. Yamauchi

Research Institute of Cultural Properties, Teikyo University, Tokyo, Japan

e-mail: yamauchi2016@main.teikyo-u.ac.jp 
Keywords Revitalization $\cdot$ Symbol $\cdot$ Memory $\cdot$ Cult-value $\cdot$ Exhibition-value

\section{An Overall Approach to Conservation and Presentation of the Property}

The hurdles in the reconstruction = restoration and the re-presentation of destroyed cultural heritages will never be overcome without implementing vigorous steps, as is the case with war, a never ceasing challenge in the history of mankind. Drastic steps must be taken and raze any prerequisites to counter this serious issue.

In Afghanistan, great progress has been made since 2002 to protect and restore the World Cultural Heritage of Bamiyan despite many obstacles. The collaborative and cooperative efforts by the United Nations Educational, Scientific, and Cultural Organization (UNESCO), international experts, and the Government of Afghanistan and the Bamiyan Province are accounted for the achievements. We believe the Revitalization of the East Buddha would be an effective tourism resource for the Bamiyan Province where peace has been sustained even while fighting still persists elsewhere in the country. We propose to utilize the Revitalization to boost overall living standards and social activity, through region developing plans including the implementation of better infrastructure, rehabilitation of housing, economic revival, and educational activities.

Buddhism has been accepted in Japan since ancient times and has continued to develop to the present day. It is an integral element of Japan's culture (culturem), and as a consequence, many Buddhist cultural heritages that were lost in disasters or wars have been restored. The Great Buddha in the Todai-ji (The Great Eastern Temple) in Nara is a prime example. The Buddha Statue has been partially recast several times after damaged. Also, murals in Horyuji's Kondo hall, which are deeply related to the Bamiyan murals, are now in the process of reproduction by patented technology of Tokyo University of the Arts. These reproductions effectively raise more awareness of the cultural heritages. Our activities in Japan, however, are not fully applicable to the Bamiyan East Buddha in the sense that the Buddha statue will not be a deity in Afghanistan where Buddhism is not a major religion. A statue of Buddha would be an idol and not be a worship image for Islamic beliefs, and because of this reason, other statues including the West Buddha and the standing Buddha in the Kakrak Valley Caves were also deliberately destructed. Respect and tolerance for other cultures take time to build as they need to be nurtured through the improvement of living standards, broad education, and cross-cultural exchange. An abrupt reconstruction of the East Buddha may potentially create friction and misunderstandings given the strong symbolic nature of Buddha. The imminent sizable cost may also prove problematic, taking into consideration that some maintenance and repair work such as niche of West Buddha and some of the important caves still have yet to be completed. 
From these perspective views, we propose the "Revitalization of the East Buddha" be a part of cultural heritage conservation and management project that embodies the broad function of a museum, taking constant profit and utilization into account as follows:

- The conservation and maintenance work on the caves situated at the south side of Hindu Kush mountains, including the two niches of the Great Buddhas, will continue under the agreement and supervision of the Bamiyan Expert Working Group Meetings.

- The Reconstruction of the East Buddha will be carried out only upon all national agreements of Afghanistan. Meanwhile, the focus will be on protecting and conserving the current condition of the site, rather than engaging in premature reproduction.

- The ongoing archaeological research around the area will confirm the location of the citadel site and the positioning of the surrounding Buddhist temple complex. After the research and excavation are completed, the Reconstruction of the Buddha should be included in the conservation plan to protect the entire World Cultural Heritage property.

- In order to fully utilize the Reconstruction of the Buddha, we need to explore the optimal way to publicize and display the statue so more people can appreciate the magnificent culture created in the Bamiyan region. In presenting the site as a "heritage with history and memory," the supplementary use of audiovisuals with recordings of the historical journey can be considered, as well as a joint display with other artifacts. We would also need to determine whether a Buddha of the original size should be created or a reduced version is more appropriate. Such deliberations are crucial to override the cult value (Kultwert) of the statue and emphasize the exhibition value (Ausstellungswert), instead.

- The Reconstruction of the Buddha should be based on bold ideas, implementing the newest technologies to inspire. What is cultural heritage if it fails to energize and enrich the lives of the inhabitants? A monument of historical testament means nothing without arousing excitement.

On these bases, we propose the following.

\section{Overall Approach on Safeguarding the Property}

\subsection{The Basic Principle on the Proposal of Revitalizing the East Buddha}

It is a wide known fact that conservation and management for World Cultural Heritage "the Cultural Landscape and Archaeological Remains of the Bamiyan Valley" (hereafter referred to as The Property) have been carried out under the guidelines and supervisions of expert working groups including the Government of Afghanistan, local community representatives, international experts, UNESCO, and 
other relevant organizations as participants. We strongly commend the continuation of the current process of safeguarding The Property and, at the same time, extend our respect to the essence of the World Heritage System as well as the activities of the respective relevant organizations.

\subsection{Proposal to Revitalization the Bamiyan East Buddha}

With the aim to promote tourism and regional development by physically revitalizing the East Buddha, we propose a building complex containing three establishments: a museum, a monument in the shape of the East Buddha and an accompanying facility, and storage for fragmented pieces of two great Buddhas.

\subsubsection{A Museum Suitable for a World Cultural Heritage}

We propose to build a museum, as its construction has been requested by the Afghan government and Bamiyan residents for some time. We will design as a unified facility with the monument in the shape of the East Buddha. It will serve to be an allinclusive central base of The Property, to display, maintain, preserve, repair, and research. We hope this facility will convey the historical significance of Bamiyan and promote a deeper understanding of The Property to the whole world and Afghan people toward reconstruction and consequently contributing to its safeguarding on many levels. The museum facility will effectively be designed as a functional building while incorporating traditional architectural structure of the Bamiyan region.

\subsubsection{A Monument in the Shape of East Buddha and an Adjoining Facility, Which New Monument Catering to Afghan People}

We propose to build an entirely new facility inclusive of a monument in the shape of the East Buddha and an adjacent establishment which would be a reproduction of the niche (hereafter the two combined will be referred to as The New Monument) in an entirely new location within the Bamiyan Valley, that located outside area of buffer zone of The Property, at the same time on a cliff that is homogeneous with the surrounding landscape. The New Monument is a reduced version of the giant East Buddha and would be constructed within the natural landscape of the Cave Garden as part of the museum.

\subsubsection{A Storage Facility to Safeguard the Remains of the Buddha}

Both of the destructed giant Buddha statues were carved out of sedimentary rocks that formed the Bamiyan Valley. Much of the remains are currently stored in a temporary facility that was constructed through a German initiative. There are many 
advocates for the fragments to be conserved as a reminder of the tragic events in the recent years. But sedimentary rocks are fragile and are vulnerable to rain and snow. In an endeavor to safeguard the remains in optimal condition, a facility where temperature and humidity can be controlled locally is imperative so they can be displayed and stored for the short to mid term. There should be a crane or a similar machine installed within the storage facility to help move heavier remains. The facility will display the remains of the Buddha and how they are carefully conserved and maintained, giving the visitors a glance of the tragic catastrophe that befell the colossal sculptures.

\section{The Guidelines for Adequate Preservation Based on the Outstanding Universal Value (OUV)}

In this section, we present the guidelines for conservation and restoration in accordance with the heritage conservation principles and global best practice, siting references from certain charters and treaties.

\subsection{The Proposed New Monument}

\subsubsection{Reason for the Construction}

As aforementioned, we propose to rebuild the East Buddha as a new monument within the Bamiyan Valley, but not within the World Heritage Property. The reason for not reconstructing the Buddha in the original niche is as follows:

(1) The tragic destruction in 2001 itself is also considered invaluable to The Property as a World Cultural Heritage. As such, reconstructing the Buddha in the original spot would undermine the OUV for The Property.

(2) The Property represents a diverse cultural landscape reflecting the rise and fall of the Buddhist culture in the area, the advancement of power of Islam, as well as the more recent global situation of the present day. In this context, the 2001 destruction also constitutes OUV.

(3) An archeological excavation and research of the original spot of the East Buddha have yet to be carried out. As such, reconstruction at the original location would be deemed as destroying archeological remains and a violation of the World Heritage Convention and other related charters.

(4) As there have been no archaeological excavation research, subgrade strength and stability need to be assessed. It is unknown whether the ground can withstand such a heavy, grand structure as the giant East Buddha, without triggering possible landslides or causing irreparable damage to other parts of The Property.

(5) (1) and (2) suggest archaeological assessment and geotechnical testing are prerequisites to reconstruct the Buddha in the original niche. In the short run, however, either would be difficult, considering the ongoing unstable situation in Afghanistan. 
(6) An overzealous attempt to reconstruct the East Buddha will not be welcomed in Afghanistan as it conflicts with the religious standard of the country. Furthermore, taking into consideration the current global situation, it is plausible that reconstruction of the Buddha statue will aggravate religious friction and prompt people with certain beliefs and ideology to intervene. Keeping in line with the World Heritage Convention that clearly notes World Heritage sites should "contribute to the maintenance of world peace," we must make sure to eliminate all possibilities of the reconstruction causing any hostility.

Building the East Buddha in the original spot seems ideal in terms of catering to the people of Afghanistan. But technological limitations and unaddressed issues make this a difficult option at the present time. We would have to account for the possible worst-case scenario that such reconstruction may even damage the components of The Property. The Bamiyan Buddhas were already once deliberately destroyed by human hands. In the process of this revitalization, we must ensure such a destruction will not be repeated regardless of whether it may be deliberate or not.

In building a brand-new monument in an entirely new spot, our proposal is within the framework of the Operational Guidelines for the World Heritage Convention and, more importantly, meets the criteria for OUV including the assessment of authenticity and integrity. This is a reflection of our appreciation, acceptance, and respect for the Operational Guidelines. In effect, our proposal to build a new monument, a museum, and storage facility would contribute to the presentation, interpretation, and education of The Property.

\subsubsection{The New Location and the Reasons for Its Selection}

The new location for the new monument was selected according to the below conditions (see Fig. 3.):

(1) It is not within the area of The Property as World Cultural Heritage.

(2) The construction of the new monument at this spot will not interfere with the cultural landscape of The Property.

(3) As it is on the cliff facing the original spot of the two Great Buddhas, it can be visually recognized by more residents.

(4) It is a location that would not intrude in the daily lives of the nearby residents.

(5) It is on a slope that bears no risk of contaminating existing rivers and furthermore, when necessary, can take protective measures on the natural spring at the foothill of the cliff. For this specific reason, the construction would be at the ridge of the slope and not at the base.

\subsubsection{The Actual Process}

(1) Construction work on the cliff surface: The local government will supervise the construction, while the Government of Afghanistan, UNESCO, and other relevant organizations will provide financial and technical support. 
(2) Build the new monument: Create the reduced size East Buddha; recreate the niche and the surrounding caves (collectively referred to as "The New Monument"). Replicate the original site pre-2001, using scientific data obtained. In this process, Tokyo University of the Arts' patented technology of cloning cultural properties will be a great contribution to recreate murals and the interiors of the caves.

(3) Building the museum: We will build a museum complex adjacent to the New Monument. The building design will be homogeneous with the surrounding environment and will not interfere with the cultural landscape. It will be built using the newest technology combined with traditional workmanship. Inside will be cave murals, corridors, and stairs along the original cave walls as well as the Buddhist complex. With the aim to educate and promote the Bamiyan history and culture, much of the remaining fragments of the destroyed Buddha will be conserved and displayed.

(4) Construction of the storage facility: A facility to preserve and maintain the remains of the Buddha statues will be built. It will be constructed in proximity to the original niches so visitors can compare the empty alcoves with the remaining fragments.

\subsection{Implementation of a Program for Adequate Protection and Management}

The Property is a World Cultural Heritage that was urgently listed following the 2001 destruction. It is also registered on the List of World Heritage in Danger. The Law on the Protection of Historical and Cultural Properties (Ministry of Justice May 21, 2004) determined by the Government of Afghanistan, The World Heritage Convention, and other relevant charters and technique in archaeology, geology, and cultural properties cultivated by relevant international organizations are all highly applicable to carry out the proposals in this section.

We propose that the new monument, museum, and storage space serve as the five pillars to secure adequate protection and management of The Property, namely, (1) to ensure stability of the Buddha niches; (2) to conserve fragments of the Buddha statues; (3) to preserve the caves; (4) to promote activity to acquire a cultural zone and corresponding economic revival; and (5) to create a sustainable tourist policy.

\subsection{Promotion of the Interpretation and Education of the Property as World Cultural Heritage}

There will be not only a new monument established at the new spot, but also a museum and storage space. These will serve to be the central base of The Property and be responsible for the display, management, conservation, repair, and research of the site. 
We can expect the following activities in the established facilities:

(1) Exhibition of archaeological remains that were already discovered and that will be recovered in future excavations.

(2) Exhibition on the historical and cultural significance of Bamiyan.

(3) Exhibitions should be simple and intuitive for visitors of all backgrounds to fully appreciate the experience.

(4) Function as an office for archaeological excavations and research activities.

(5) Function as an office to safeguard the overall property of the World Heritage.

(6) Facilities such as conference rooms available on the premises to hold trainings and meetings.

The management of the museum complex should be discussed and established under internationally collaborative auspices. In terms of safeguarding The Property, cooperation and aid of the Ministry of Information and Culture, with its relevant sections (The Institute of Archaeology and the Department for Protection and Rehabilitation of Historical Monuments), are desirable as they have local offices. Provision of the necessary personnel, including security guards and police forces, that have already been involved in protecting the ruins is also indispensable.

\subsection{Implementation of a Program for Cultural Tourism with Short-, Mid-, and Long-Term Visions}

The objective of the program will be to promote The Property in the framework of World Cultural Heritage Tourism and to encourage regional development. The construction and management of the new monument, museum complex, and the storage facility would not only facilitate the protection and management of The Property but also be a tourism resource for the promotion of cultural tourism. In addition, we can anticipate the below developments:

Tangible developments:

(1) Transport infrastructure, such as roads and signs around the site, will be placed to accommodate visitors' safety and accessibility.

(2) Facilitate a quick formulation of Bamiyan's urban planning to keep its current distinctive landscape. The plan is inclusive of the traditional land use and the buildings made of mud bricks which serve to maintain the value of the Property as a cultural resource.

Intangible developments:

(1) Provision in educational services for the nearby residents as well as tourists

(2) Improvement in employment and vocational opportunities to secure personnel for research, conservation, and management of The Property. 


\subsection{Addressing the Wishes of Local Communities}

The ultimate goal of the Buddha revitalization is to reflect the ideas and hopes of the local community. Most of the local people are farmers who have been farming in Bamiyan from long before the demolition of the Buddha. It is our understanding that they desire the reconstruction of the Buddha in anticipation of the potential income gain that The Property could generate as a tourism resource in the framework of World Cultural Heritage. In light of that assumption, we will clarify how our proposal can fulfill the anticipation of the local community and secure resources for regional development.

Firstly, the new monument and museum would generate new sources of tourism that go beyond the scope of simply rebuilding the East Buddha. This is highly effective as a short-term measure for cultural tourism. In addition, a museum exhibition would provide accurate historical and cultural information to the visitors, thereby strengthening the appreciation of protecting the heritage and spreading the understanding and awareness of the situation surrounding The Property. This would be a mid- to long-term contribution to cultural tourism.

Secondly, in keeping with the efforts to safeguard the World Cultural Heritage property inclusive of the destroyed Buddha, we endeavor to sustain and further enhance the mid- to long-term value of The Property as a cultural resource. To achieve this, we will naturally continue to operate the conservation and management plans formulated and supervised by the Government of Afghanistan, UNESCO, and its relevant organizations but will also make enhancements to facilitate visiting The Property (inclusive of the new infrastructure that will be constructed for the new monument), by building new corridors and steps and displaying signs with descriptions. Safeguarding efforts may initially be led by international assistance, but the task will eventually need to be taken over by the Government of Afghanistan and the local government to build the necessary foundation for a sustainable cultural tourism.

Thirdly, and finally, the new monument shall be located at the new location, which is visible to locals. Such revitalized image within the landscape of the Bamiyan Valley would recall the locals the original landscape of the valley.

We aspire for these three concepts to resonate with the people who affectionately long for the reconstruction of the East Buddha as well as those who count on regional development and a boost income. Our aim is to develop the local history and culture, strengthening identification which would advocate sustainable tourism in the short, mid, and long term. 


\section{Technical Overview on the Reproduction of the Eastern Buddha}

\subsection{The Location of the Reproduction}

The two empty niches of the giant Buddha statues are carved into the Great Cliff soaring over $100 \mathrm{~m}$. The statues, destroyed by the Taliban in 2001, were a part of the numerous caves of Buddhist monasteries, temples, and sanctuaries tucked away in these cliffs. These sites should be well protected and carefully preserved as cultural heritage for mankind. We build the monument in the shape of Eastern Buddha and the museum in another place without reconstructing the Bamiyan Buddha statues in this place (Fig. 1). There are three proposed sites (see Fig. 2), but this report outlines the design that is assumed to locate on the site (1) which is adjacent to the Bamiyan Culture Center designed by an Argentinian team and adopted by UNESCO in 2015.

The Great Cliff lies in the Bamiyan Valley, running across about $1 \mathrm{~km}$ in width. On the opposite side of the valley, 40-m- to 50-m-high plateaus with a scarp of about $45^{\circ}$ are located. These plateaus are planned to be the designated area for promoting and supporting artistic and cultural processes.

We plan to reproduce the Eastern Buddha and its niche, originally situated at the Great Cliff, at the tip of one of these plateaus. This new site would be a part of the museum which will conserve and display the remnants of the destroyed Buddha and other significant artifacts. The site is in the Cave Garden designed in Japan's proposal "Bamiyan Museum \& Culture Center for People (Website http://www.

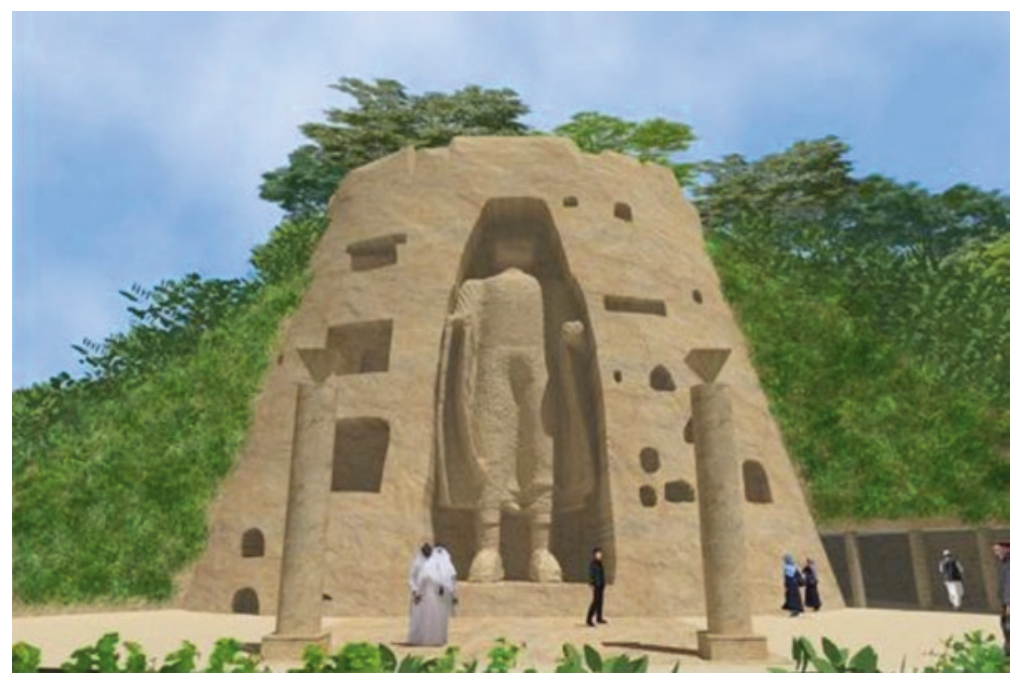

Fig. 1 Frontal view of the monument: the entrance of the staircase that leads to the museum and the top of the plateau is on the left side of the monument. (@ Shigeyuki Okazaki/ Tokyo University of the Arts) 


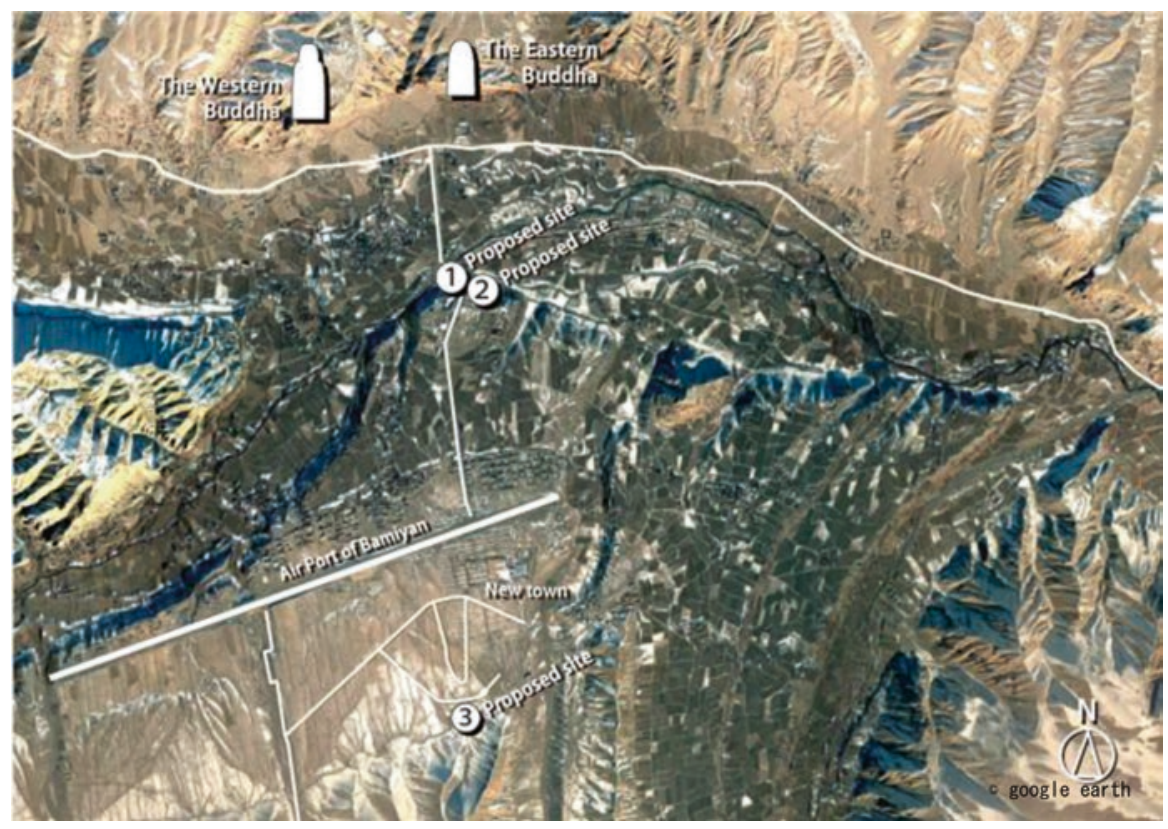

Fig. 2 Three possible sites for constructing the monument and the museum. (@ google earth)

mukogawa-u.ac.jp/ bamiyan/index_2013.html)," presented at the 12th Bamiyan Expert Working Group Meeting in Orvieto, Italy, in December, 2013.

\subsection{Proportion of the Reproduced Eastern Buddha}

While a full-scale reproduction is ideal, it is quite difficult to find a cliff or plateau that accommodates a huge 38 meter statue and 41 meter niche in height. Only a cliff that stands almost perpendicular to the ground, such as the Great Cliff, would meet our needs. It is not feasible to build a 41 meter niche into the slope on the south side of the Valley as it is about 40 meter height with an inclination angle of $45^{\circ}$. Alternatively, a stand-alone construction in front of the slope of the plateau should also be ruled out considering the compatibility with the surrounding landscape. The height of the Great Cliff that includes the Eastern Buddha corresponds to a modern high-rise building. If we reconstruct the Eastern Buddha statue in its original size, such a huge structure would be incompatible with the place that consists of smallscale villages, rivers, roads, and public squares in the area.

After much deliberations and scrutiny using computer graphics, models, and diagrams, we concluded to reproduce a 13-meter-height Buddha that is one-third of the original Eastern Buddha (Figs. 3, 4, 5 and 6). 


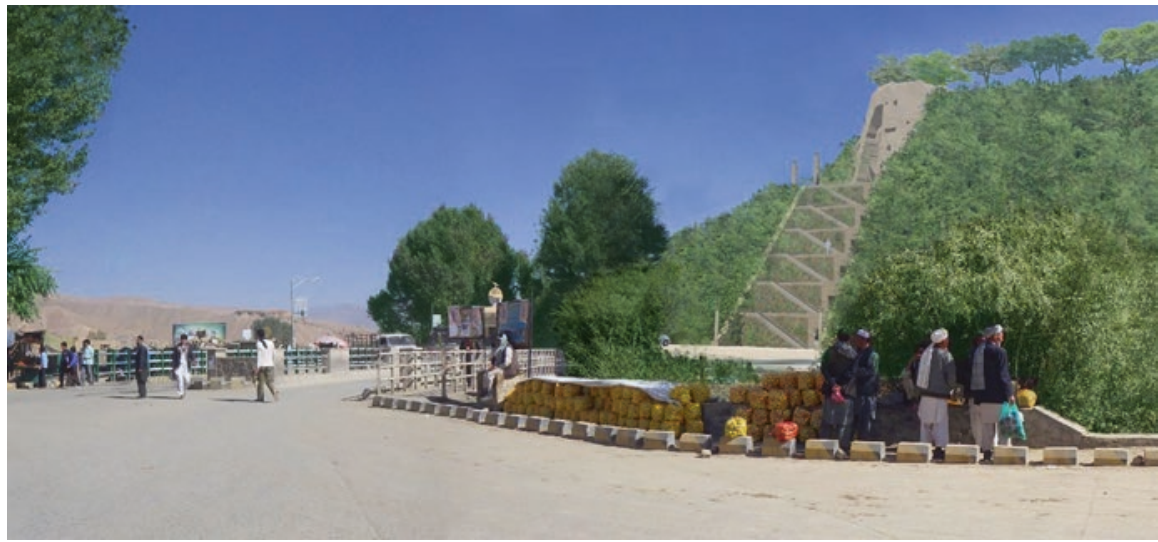

Fig. 3 Composite photo of the proposed monument and the existing landscape. (@ Shigeyuki Okazaki/ Tokyo University of the Arts)

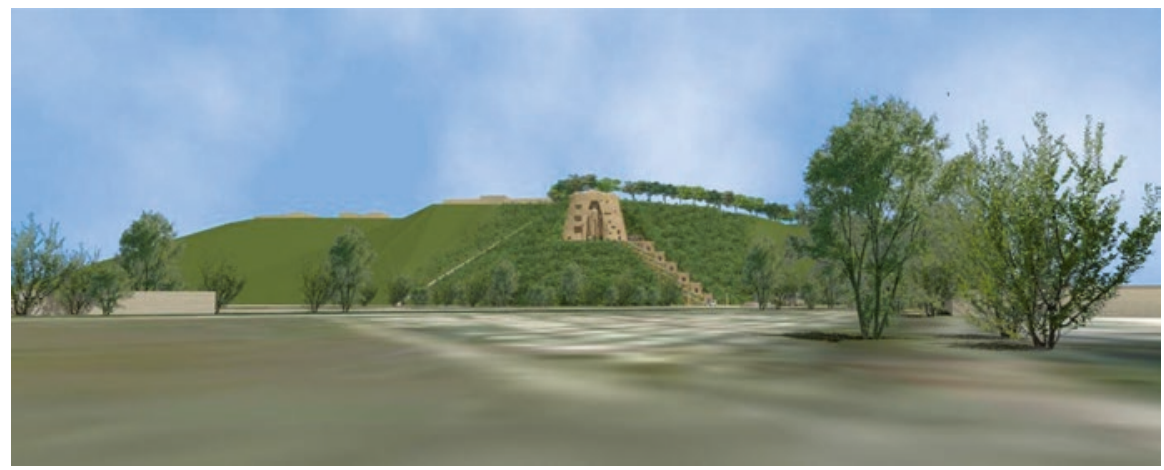

Fig. 4 Frontal view of the monument from the bottom of the Bamiyan Valley. (@ Shigeyuki Okazaki/ Tokyo University of the Arts)

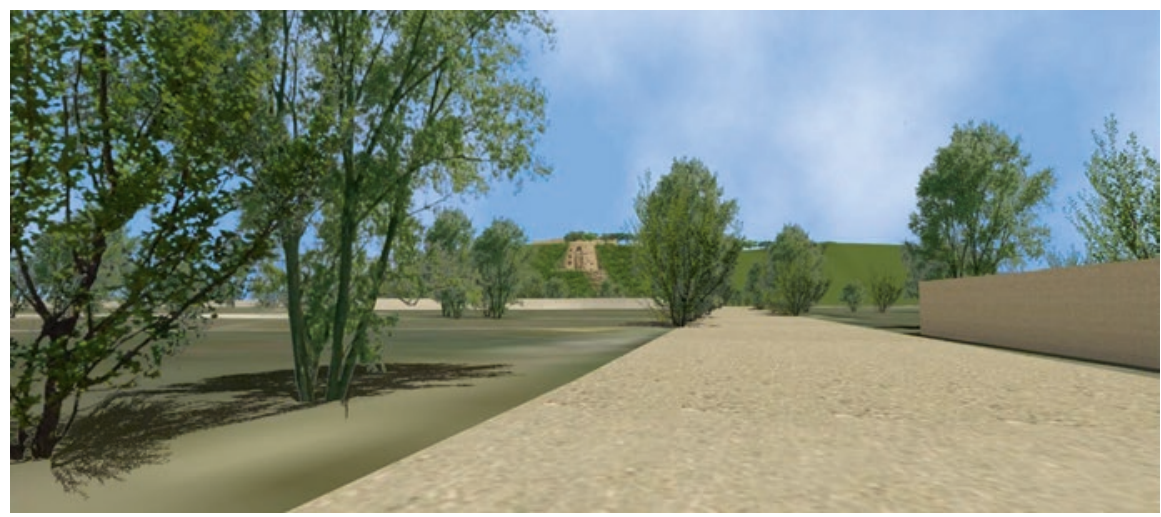

Fig. 5 View of the monument from the tree-lined street on the Bamiyan Valley. (@) Shigeyuki Okazaki/ Tokyo University of the Arts) 


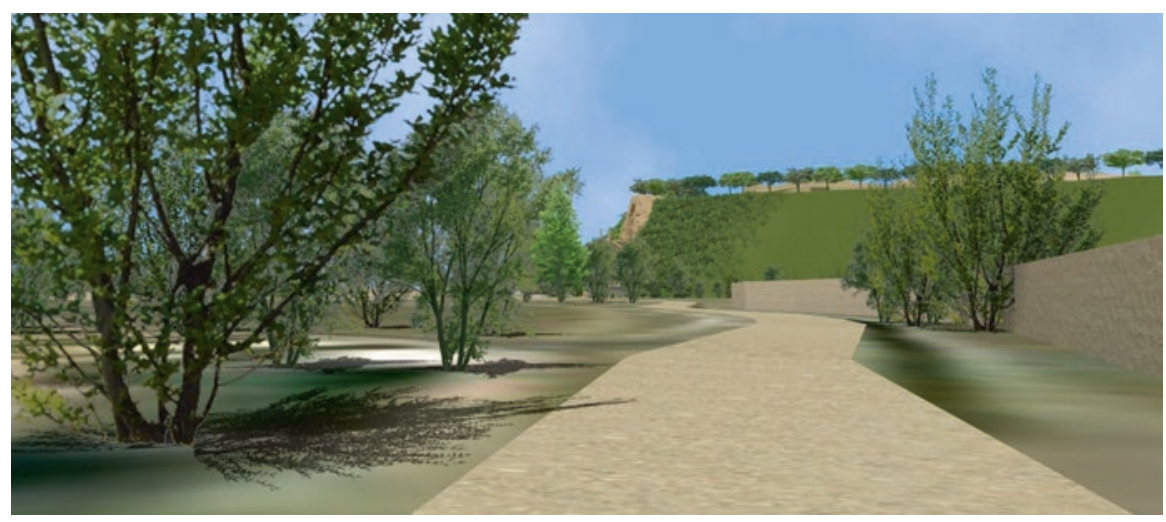

Fig. 6 View of the monument from the tree-lined street on the Bamiyan Valley. (@ Shigeyuki Okazaki/ Tokyo University of the Arts)

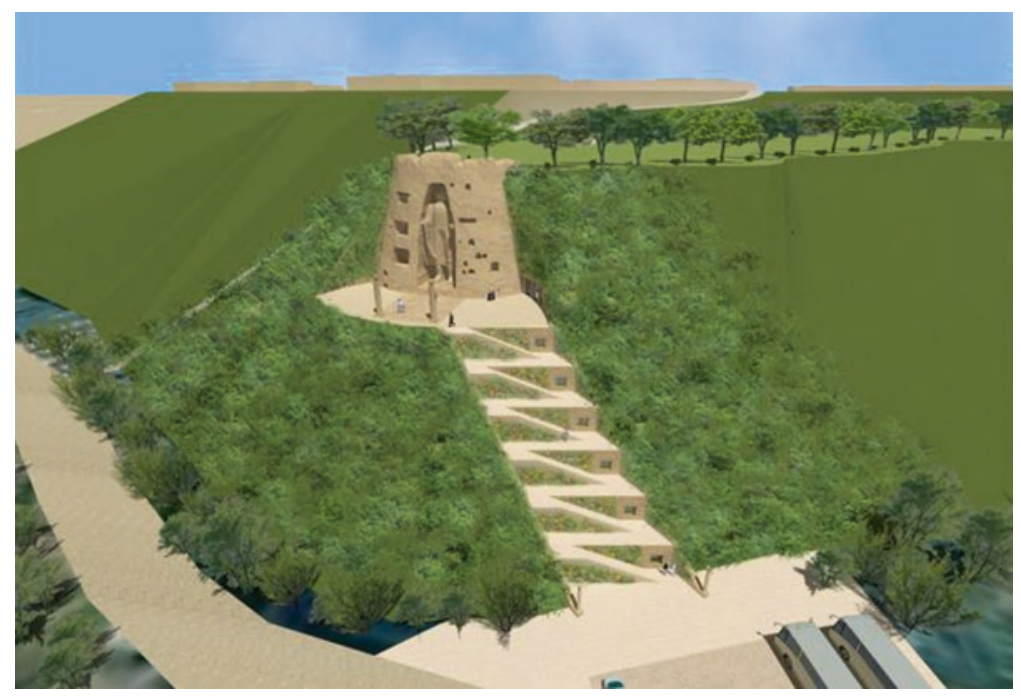

Fig. 7 Bird's eye view of the proposed monument from the north: a one-third scale of the Eastern Buddha is constructed on the platform halfway up the hillside. The outdoor steps connect the foot of the plateau and the platform. (@ Shigeyuki Okazaki/ Tokyo University of the Arts)

\subsection{Direction of the Front Side of the Reproduced Eastern Buddha and the Axis Connecting the Monument and the Western Buddha Niche}

We plan to reproduce the monument in the shape of Eastern Buddha on the platform halfway up the hillside. The outdoor steps connect the foot of the plateau and the platform (Fig. 7). Visitors ascend toward the monument along the slope. The stairs 

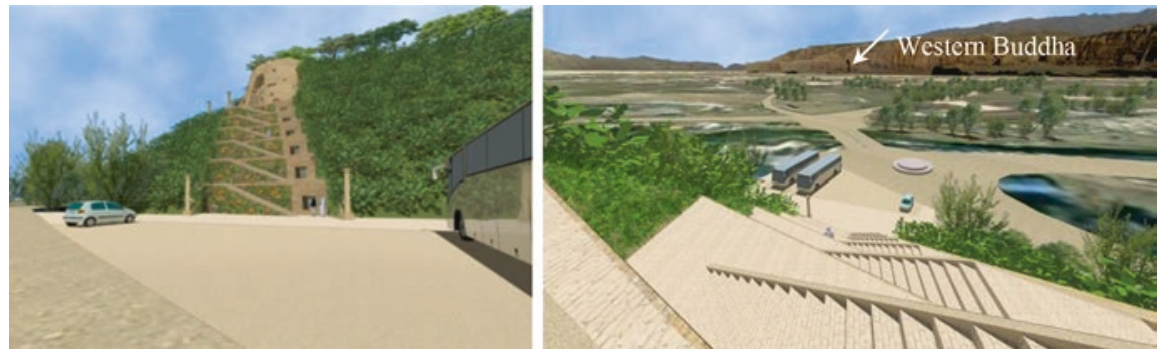

Fig. 8 The axis connecting the monument and the Western Buddha niche: the outdoor steps on the axis that lead to the platform (left). View of the outdoor steps, the Bamiyan Valley, and the Great Cliff from the platform: the Western Buddha is located on the axis of the steps (right). (@ Shigeyuki Okazaki/ Tokyo University of the Arts)
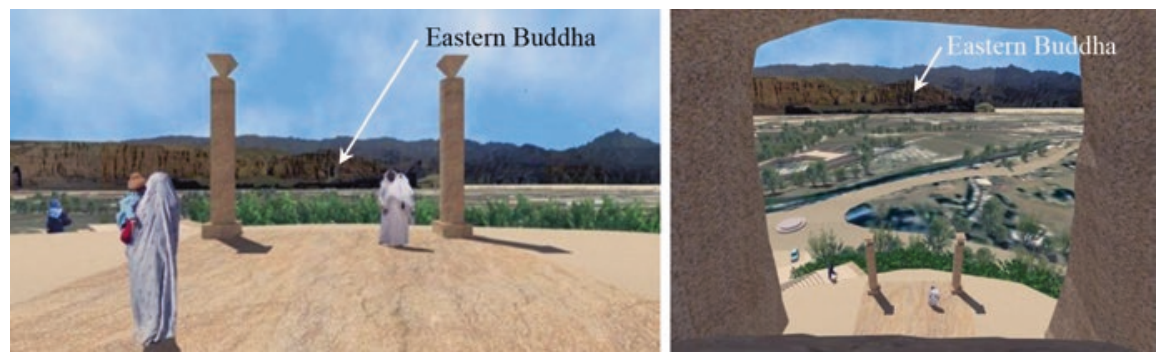

Fig. 9 The axis connecting the monument and the Eastern Buddha niche: the one-third scale Buddha faces the Eastern Buddha squarely (left). View of the Bamiyan Valley and the Great Cliff from the observatory on the top of the one-third scale Buddha (right). (๔ Shigeyuki Okazaki/ Tokyo University of the Arts)

will be situated on the axis line connecting the monument and the Western Buddha niche. In other words, when people go down the stairs, they will go down toward the Western Buddha niche (Fig. 8). On the other hand, the reproduced Eastern Buddha and its niche will face toward the empty niche of the Great Cliff in which the original Eastern Buddha was located (Fig. 9).

\subsection{Channel and Springs on the Outdoor Steps}

A channel will be built in the outdoor steps to water plants. Every flat space on the steps has a spring whose water provided through the channel. These channel and springs would help the slopes, and the green wall surfaces stay lush with greenery and flowers (Fig. 10). 


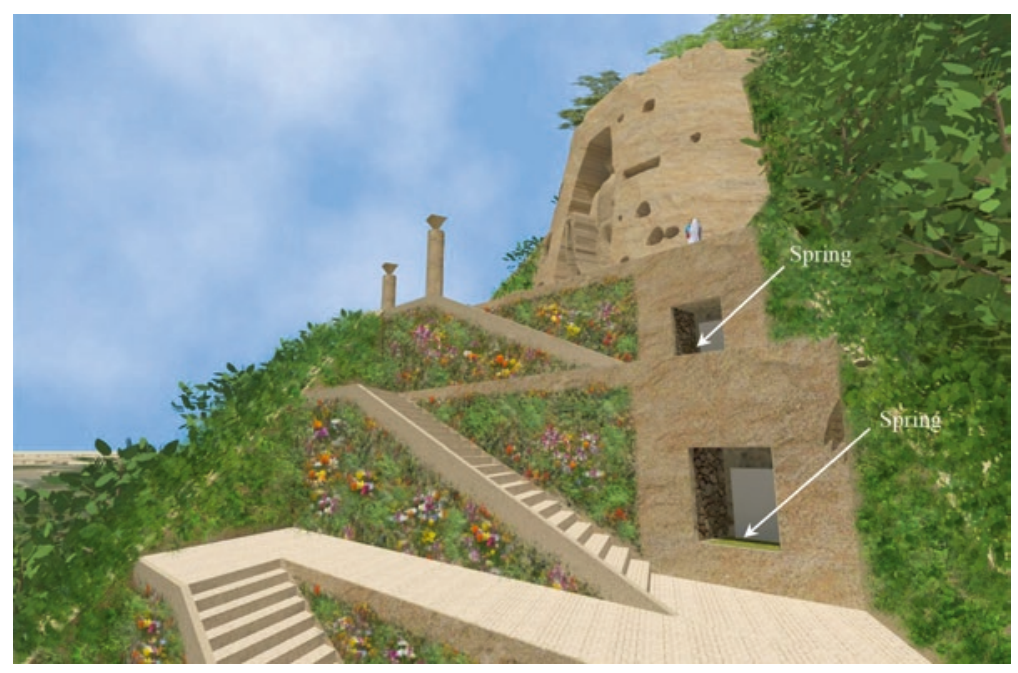

Fig. 10 A spring on every flat space of the outdoor steps to water plants. (@ Shigeyuki Okazaki/ Tokyo University of the Arts)

\subsection{Materials, Structure, and Construction of the Monument}

It is extremely complicated to reproduce the statue inside the original niche using materials such as reinforced concrete. The original Buddhas and the niches were simultaneously carved into the natural cliff. To construct a new Buddha inside the original niche, however, would be equivalent to build a huge and heavy load structure in the empty space. The reconstructed Buddha seems like a cantilever, rising up from the ground surface. The new Buddha may also be supported by the rear side of the niche. However, handling of the vertical force and the horizontal force on the terrain in case of an earthquake should be addressed. In addition, if surrounding walls in the niche support the horizontal force, we would need to handle sustaining power of the walls against the horizontal force. In any case, we need to assess if the current state of the Cliff allows us to perform these treatments against the vertical force and the horizontal force. Furthermore, cost of the reinforcing treatments should also be considered.

As for the new Buddha to be reproduced, we propose to use lightweight materials, such as glass fiber reinforced concrete (GRC). The use of GRC includes spraying of concrete with grass fiber to a shaped 3D steel mesh. For this reason, we do not need to prepare a negative mold of the Buddha. These efforts paved the way to create extraordinary new designs by the material, including their more recent success of combining GRC with different materials such as glass and stones. The cost of the construction using GRC is shown in Fig.11. 


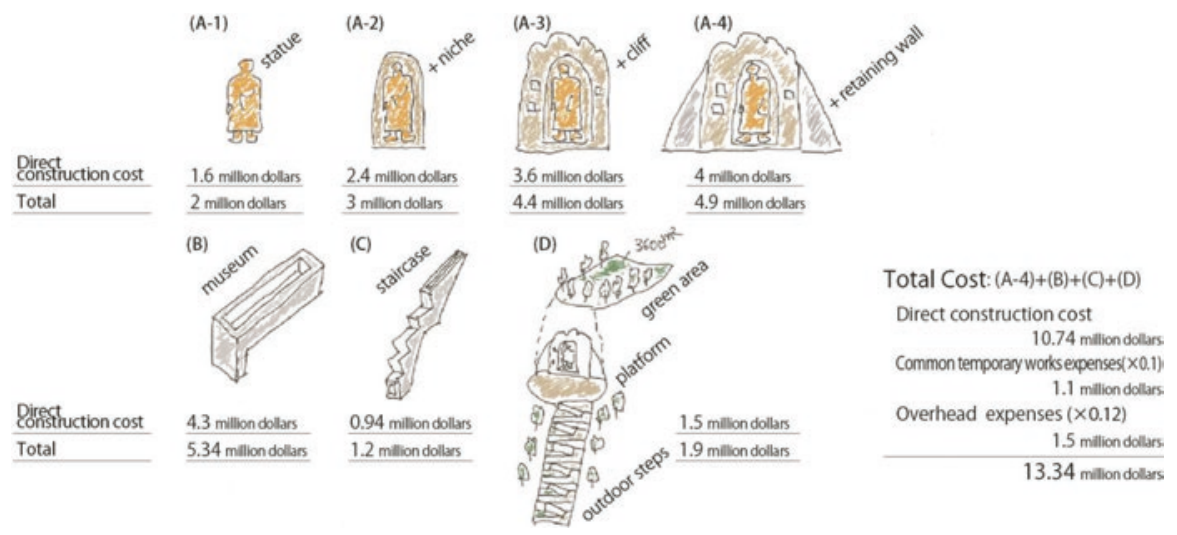

Fig. 11 Cost of the construction for each part. (C Shigeyuki Okazaki/ Tokyo University of the Arts)

\subsection{Plan of the Monument and the Museum (Figs. 12, 13, 14, 15 and 16)}

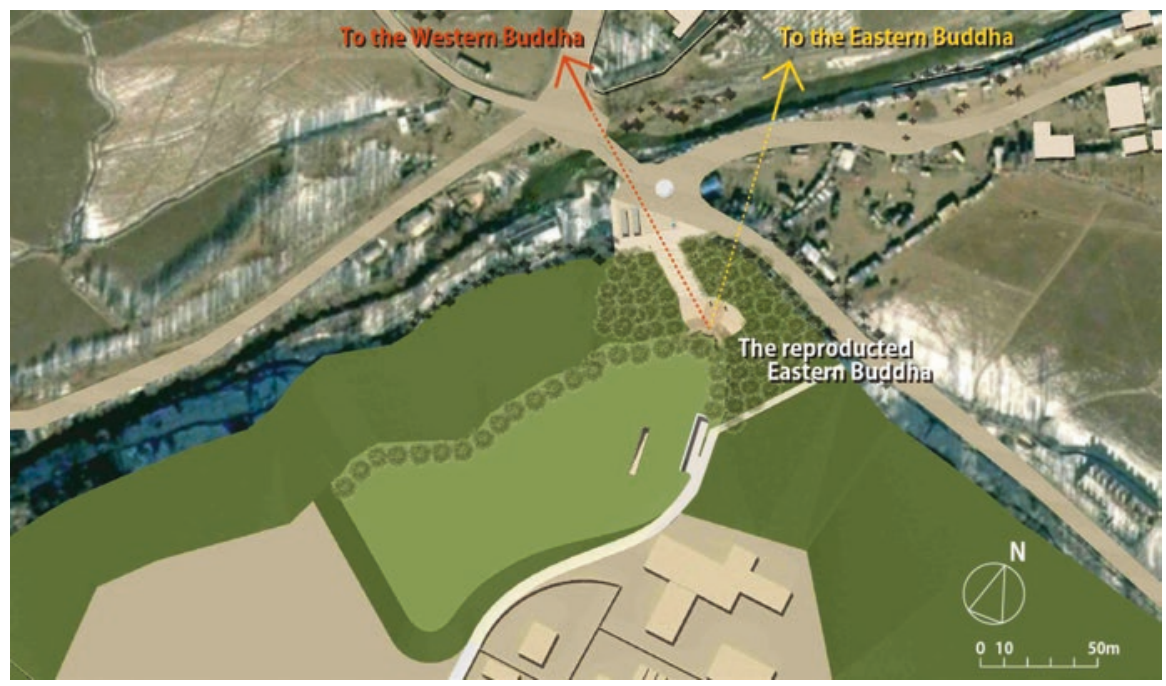

Fig. 12 Site plan: the monument (a one-third scale of the Eastern Buddha statue) faces the real Eastern Buddha squarely. The Western Buddha statue is located on the axis of the outdoor steps. The underground museum is constructed in the back of the monument. (@ Shigeyuki Okazaki/ Tokyo University of the Arts) 


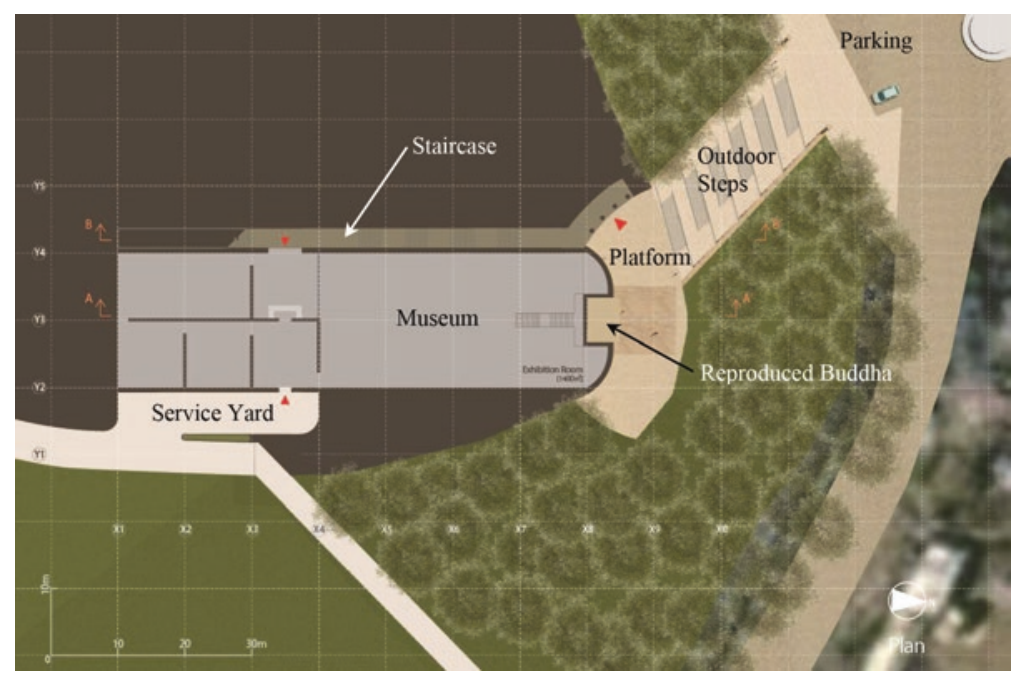

Fig. 13 Basement plan of the museum and the plan of the platform: the staircase connects the platform, the entrance of the museum, and the top of the plateau. (@ Shigeyuki Okazaki/ Tokyo University of the Arts)

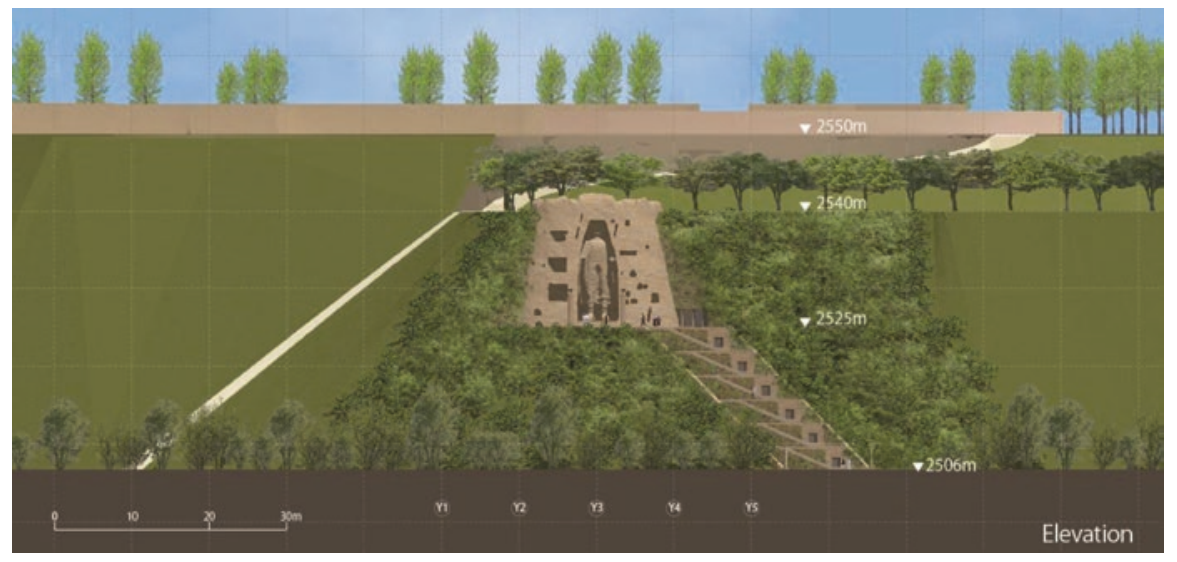

Fig. 14 Southeast elevation. (@ Shigeyuki Okazaki/ Tokyo University of the Arts) 


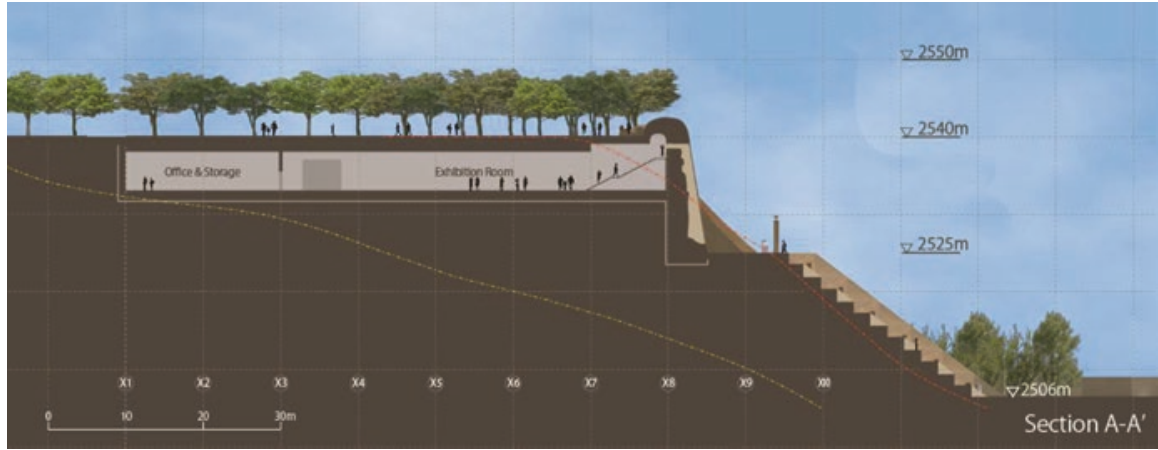

Fig. 15 Section of the museum: the yellow and red dotted line represents the existing ground level of the museum area and outdoor steps area, respectively. (@) Shigeyuki Okazaki/ Tokyo University of the Arts)

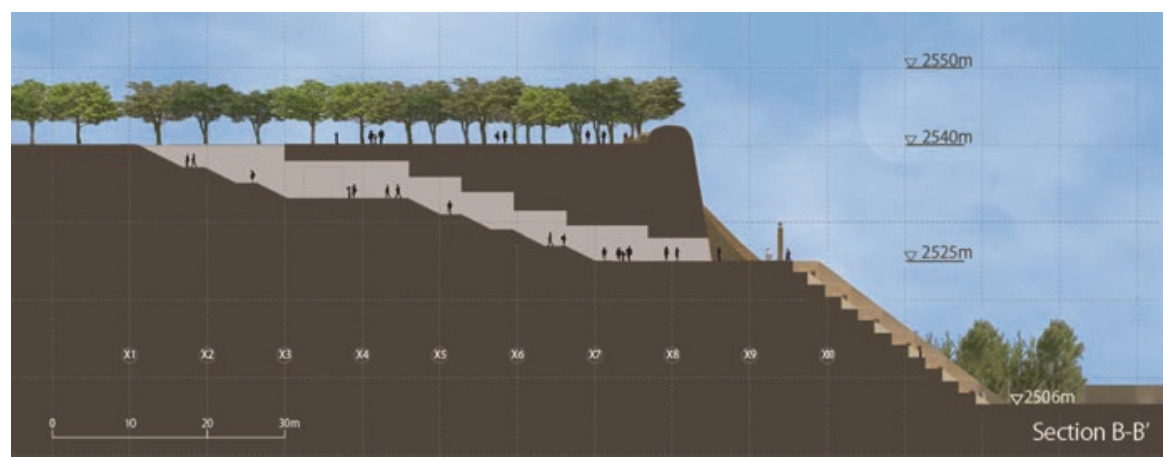

Fig. 16 Section of the staircase that connects the platform and the top of the plateau. (@) Shigeyuki Okazaki/ Tokyo University of the Arts) 
The opinions expressed in this chapter are those of the author(s) and do not necessarily reflect the views of the UNESCO, its Board of Directors, or the countries they represent.

Open Access This chapter is licensed under the terms of the Creative Commons AttributionShareAlike 3.0 IGO License (https://creativecommons.org/licenses/by-sa/3.0/igo/), which permits use, sharing, adaptation, distribution, and reproduction in any medium or format, as long as you give appropriate credit to UNESCO, provide a link to the Creative Commons licence and indicate if changes were made. If you remix, transform, or build upon this chapter or a part thereof, you must distribute your contributions under the same licence as the original. This publication is also available at the UNESCO Open Access Repository: https://unesdoc.unesco.org/

The designations employed and the presentation of material throughout this publication do not imply the expression of any opinion whatsoever on the part of UNESCO concerning the legal status of any country, territory, city or area or of its authorities, or the delimitation of its frontiers or boundaries.

The authors are responsible for the choice and the presentation of the facts contained in this chapter and for the opinions expressed therein, which are not necessarily those of UNESCO and do not commit the Organization.

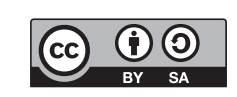

